\title{
Process-based simulation of contrail cirrus in a global climate model
}

\author{
Ulrike Burkhardt $^{1}$ and Bernd Kärcher ${ }^{1}$ \\ Received 19 November 2008; revised 27 May 2009; accepted 4 June 2009; published 20 August 2009.
}

[1] Aviation induces changes in global cirrus cloudiness by producing contrails. In the past, line shaped contrail coverage has been parameterized relying on the scaling of contrail formation frequency to observed values. Coverage due to irregularly shaped contrail cirrus, that develop from line shaped contrails, could not be estimated with this method. We introduce a process-based parameterization of contrail cirrus in a global climate model that does not rely on scaling and that is not restricted to line shaped contrails. A new prognostic cloud class, contrail cirrus, is introduced that is allowed to develop in the parameterized, fractional ice supersaturated area. Initial dimensions of the contrails and a parameter controlling their spreading in a sheared flow are constrained by observational data. In an idealized experiment contrail cirrus coverage is found to be dominated by a major contrail outbreak and scales with supersaturation rather than contrail formation frequency. The global distribution of young contrail coverage is smoothed out due to transport but overall values are similar compared to older estimates. Interannual variability of young contrail coverage can be as large as the mean coverage. The sensitivity of the model simulations to physical model parameters and to parameters concerning the comparison with observational data is studied. The associated uncertainty of global line shaped contrail coverage can be as high as $60 \%$ of the reference estimate $(0.05 \%)$. The simulated coverage due to young contrails agrees reasonably well with most satellite observations of regional line shaped contrail coverage considering the sensitivity to the above parameters and the interannual variability.

Citation: Burkhardt, U., and B. Kärcher (2009), Process-based simulation of contrail cirrus in a global climate model, J. Geophys. Res., 114, D16201, doi:10.1029/2008JD011491.

\section{Introduction}

[2] Changes in global cirrus cloudiness are the least known component of aviation induced climate change. Aviation induced contrails exert a nonnegligible radiative forcing on climate [Forster et al., 2007]. Global radiative forcing due to line shaped contrails for the year 2000 is estimated, using global atmospheric models, to be approximately $10 \mathrm{~mW} / \mathrm{m}^{2}$ [Sausen et al., 2005]. Radiative forcing due to line shaped contrails is predicted to increase significantly in a future climate due to the expected rise in air traffic [Marquart et al., 2003], increasing the contribution of air traffic to climate change. Neither the current nor the future global coverage and radiative effect due to contrail cirrus, which originate from line shaped contrails, could be simulated.

[3] Line shaped contrails can be identified in satellite images as long as the contrast in brightness temperature between the contrails and their surrounding is large enough. This contrast depends on the optical depth of the contrails, their geometric extent, the presence of natural clouds, the underlying surface conditions and many other factors.

\footnotetext{
${ }^{1}$ Institut für Physik der Atmosphäre, Deutsches Zentrum für Luft- und Raumfahrt, Oberpfaffenhofen, Germany.

Copyright 2009 by the American Geophysical Union. 0148-0227/09/2008JD011491\$09.00
}

Regional estimates of line shaped contrail coverage have been inferred using satellite images [Bakan et al., 1994; Meyer et al., 2002, 2007; Minnis et al., 2005; Palikonda et al., 2005]. Coverage due to line shaped contrails appears to be highly variable. When atmospheric conditions are favorable, in ice supersaturated areas which are often situated downstream of frontal systems [Detwiler and Pratt, 1984; Kästner et al., 1999; Carleton et al., 2008], coverage due to line shaped contrails can be very large. Studies using satellite imagery indicate that line shaped contrail coverage can be as large as $3 \%$ in regions extending up to $60,000 \mathrm{~km}^{2}$ [e.g., Duda et al., 2004]. These situations are referred to as contrail outbreaks. Nevertheless actual contrail coverages may be higher since contrails may be concealed by natural clouds or may not be detectable by passive remote sensing. Individual contrails have been observed to exist for at least $17 \mathrm{~h}$ [Minnis et al., 1998], transforming into contrail cirrus that is often not distinguishable from natural cirrus impeding observation-based estimates of contrail cirrus coverage and their radiative forcing. In order to circumvent this identification problem, trends in high cloud coverage have been correlated with air traffic density [e.g., Boucher, 1999; Stubenrauch and Schumann, 2005; Eleftheratos et al., 2007]. Even if these inferred trends were solely due to aviation, they are due to the combined effects of aircraft soot emissions on natural cirrus and contrail cirrus. 
[4] Observations have shown that microphysical and optical properties of young contrails are different from cirrus [e.g., Betancor-Gothe and Grassl, 1993; Schumann et al., 1996; Sassen, 1997; Schumann, 2005; Febvre et al., 2009]. Other measurements have indicated that contrail ice particle size distributions tend to change resembling eventually small ice particle modes detected in natural cirrus [Schröder et al., 2000] or develop large ice crystals in highly supersaturated layers resembling those found in cirrus both in number concentration and shape [Heymsfield et al., 1998].

[5] In order to estimate the global effect of line shaped contrails, their coverage has been estimated using reanalysis data combined with a flight inventory [e.g., Sausen et al., 1998; Gierens et al., 1999a; Myhre and Stordal, 2001; Minnis et al., 2005; Stuber and Forster, 2007; Rädel and Shine, 2008]. Duda et al. [2005] used the same method to analyze line shaped contrail coverage over the U.S.A. only. Ponater et al. [2002] and Marquart [2003] implemented a diagnostic contrail parameterization in a Global Climate Model (GCM). This parameterization consists of calculating the area in which the formation and persistence criteria are fulfilled (potential contrail coverage), folding this potential contrail coverage at each GCM time step with the actual air traffic density and scaling the resulting contrail formation frequency to give the observed mean coverage in a specified area. The resulting scaling coefficient is then assumed to be globally and temporally constant, which allows the calculation of an instantaneous global line shaped contrail coverage at every model time step and for each model grid box. The contrail's ice water content is diagnosed from the model's water vapor available for deposition on cloud ice particles at each time step.

[6] While the above GCM parameterization allowed the calculation of contrail coverage, optical properties and radiative impact within the climate model, it also has important conceptual limitations. Inferring contrail coverage from the contrail formation frequency is physically doubtful since contrail lifetimes and spreading rates are variable in time and space. The method does not capture the advection of contrails, which is not negligible considering that individual contrails can have lifetimes of many hours. The use of the scaling coefficient, inferred from observational data, limits the method to line shaped contrails due to the absence of observational estimates of contrail cirrus coverage. Contrail ice water content should not be diagnosed but instead evolves temporally just as the ice water content of natural clouds.

[7] Therefore, the motivation of the present study is to overcome the deficiencies of the old scheme and simulate contrail cirrus coverage and ice water content for the first time based on the parameterization of physical processes instead of based on the tuning to an observed coverage and diagnosing its ice water content from the available water vapor. In section 2 , a new method to predict contrail cirrus coverage and ice water content based on the parameterization of the physical processes governing the two quantities in a GCM framework is presented. Contrail cirrus is introduced as a separate ice cloud type of anthropogenic origin in the GCM allowing contrails to have a different ice water content and therefore different optical properties than natural clouds as is observed for young contrails. Relevant processes in the parameterization are the generation of new contrails, their transport and spreading as well as the depositional growth, sublimation and precipitation of their ice water content. The parameterization of spreading requires the introduction of a third prognostic variable, contrail length. The fractional ice supersaturated area, the area in which contrails can persist, is parameterized [Burkhardt et al., 2008]. The prognostic treatment of all three variables allows the simulation of the development of contrail cirrus from formation to dissipation. The contrail cirrus module allows the discrimination of young contrails (age $<5 \mathrm{~h}$ ) from older contrail cirrus. This discrimination has only been introduced in order to compare to observations and simulations of line shaped contrail coverage. An idealized experiment (section 3 ) is conducted to study the performance of the contrail cirrus module. In section 4, coverage due to contrails, exceeding a certain age and optical depth threshold, is analyzed using a recent (year 2002) air traffic inventory. The sensitivity of the resulting coverage to uncertainties, when constraining physical parameters in the parameterization, and to thresholds, regarding the comparison of the results with observations, has been analyzed. Several issues that currently impede a more detailed model validation are highlighted. The study concludes with a validation of the contrail cirrus module using the only available observational basis suitable for GCM validation, observed regional line shaped contrail coverage. The scheme and its validation are prerequisites for further studies of contrail cirrus and their interaction with the natural cloud and moisture field.

\section{Contrail Cirrus Module}

[8] We implemented a contrail cirrus module in the ECHAM4/L39 climate model [Roeckner et al., 1996; Land et al., 1999] at T30 resolution. This corresponds to a horizontal distance between Gaussian grid boxes in $50^{\circ} \mathrm{N}$ of $270 \mathrm{~km}$. The 39 levels correspond to a vertical resolution of about $700 \mathrm{~m}$ in the upper troposphere and lowermost stratosphere where contrails mainly form. The model was run using a time step of $30 \mathrm{~min}$. The module simulates the aggregated effect of air traffic within each model grid box. Air traffic is prescribed by the AERO2k flight inventory [Eyers et al., 2004] prescribing annual total flight distances of $17.9 \times 10^{9}$ nautic miles and total water vapor emissions of $193 \mathrm{Tg}$.

[9] The module consists of prognostic equations for the additional model variables fractional contrail cirrus coverage, aggregated contrail length and grid mean contrail cirrus ice water mass mixing ratio. The dynamical and microphysical processes governing the development of those three variables are parameterized. Contrails and contrail cirrus are allowed to form and spread in ice supersaturated but cloud free areas. In the absence of explicit (i.e., resolved on the grid scale) supersaturation in the host model ECHAM4, cloud free supersaturated areas have been parameterized [Burkhardt et al., 2008]. In our model, described below, contrail cirrus and natural cirrus interact by competing for available water vapor and by changing the relative humidity field, the formation frequency of contrails and cirrus and the radiative fluxes. 


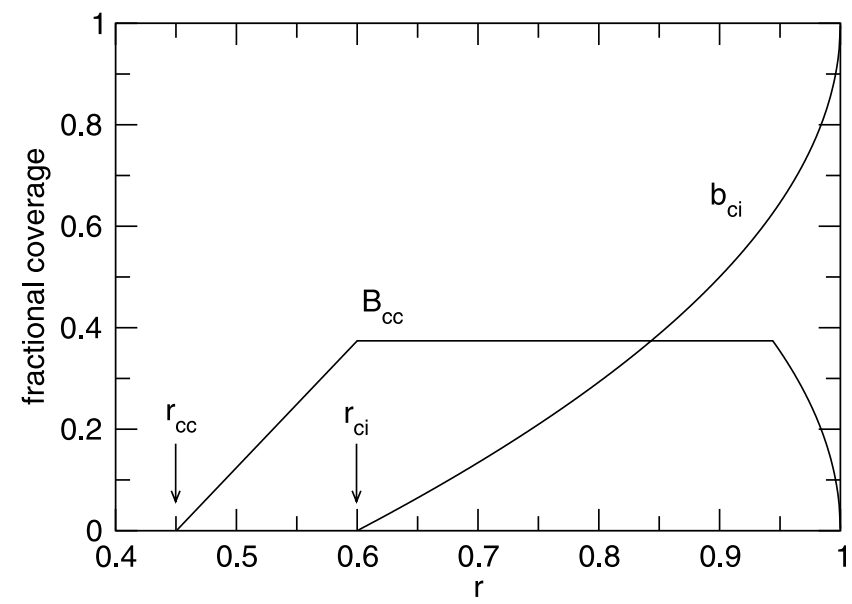

Figure 1. Fractional natural cirrus coverage, $b_{c i}$, and cloud free ice supersaturated area (potential contrail cirrus coverage), $B_{c c}$, versus grid mean relative humidity, $r$. Critical humidities above which a fraction of the grid box is covered by cirrus and is ice supersaturated are denoted by $r_{c i}$ and $r_{c c}$, respectively. $r_{c c}$ is derived from $r_{c i}$ at a temperature of $225 \mathrm{~K}$.

\subsection{Prognostic Equations}

[10] The local rates of change for contrail cirrus fractional coverage $b$, contrail length $\mathrm{L}$ aggregated over the grid box and grid mean ice water mass mixing ratio $m$ are given by

$$
\begin{gathered}
\frac{\partial b}{\partial t}=\left(\frac{\partial b}{\partial t}\right)_{\mathrm{tsp}}+\left(\frac{\partial b}{\partial t}\right)_{\mathrm{spr}}+\left(\frac{\partial b}{\partial t}\right)_{\mathrm{sub}}+\left(\frac{\partial b}{\partial t}\right)_{\mathrm{new}} \\
\frac{\partial \mathrm{L}}{\partial t}=\left(\frac{\partial \mathrm{L}}{\partial t}\right)_{\mathrm{tsp}}+\left(\frac{\partial \mathrm{L}}{\partial t}\right)_{\mathrm{sub}}+\left(\frac{\partial \mathrm{L}}{\partial t}\right)_{\text {new }} \\
\frac{\partial m}{\partial t}=\left(\frac{\partial m}{\partial t}\right)_{\mathrm{tsp}}+\left(\frac{\partial m}{\partial t}\right)_{\mathrm{dep}}+\left(\frac{\partial m}{\partial t}\right)_{\mathrm{prc}}+\left(\frac{\partial m}{\partial t}\right)_{\text {new }}
\end{gathered}
$$

All three variables are transported (subscript 'tsp') in the model by horizontal and vertical advection, convection and vertical diffusion in the same way as tracers. When the contrail formation criterion is fulfilled, $b, \mathrm{~L}$ and $m$ can change due to newly developing contrails ('new') that contain initially only water vapor released by the airplane. Contrails spread ('spr') due to the vertical shear of the horizontal wind field. They can accumulate ice mass $m$ by deposition of available moisture ('dep') and precipitate ('prc') if the ice mass becomes large. If contrails experience ice subsaturations, ice sublimates and reduces $m$, which is integrated as the reverse process in the deposition tendency for $m$. Partial sublimation or precipitation does not alter $b$ and L, but if all the ice sublimates ('sub') or precipitates, the contrail cirrus disappears. The tendencies for new contrail formation are calculated from source terms $b_{\text {new }}, \mathrm{L}_{\text {new }}$ and $m_{\text {new }}$ divided by the GCM model time step. Individual terms in equations (1), (2) and (3) are discussed in the following sections. We will also refer to the specific ice water content, defined by IWC $=\rho \cdot m / b$, where $\rho$ is the mass density of air.

[11] Fractional contrail coverages and lengths that develop at different integration time steps are tracked independently for up to $5 \mathrm{~h}$ before they join the general contrail cirrus cloud class. This allows the analysis of the coverage due to young contrails. Assuming that young contrails are those that are most likely to be still line shaped, this enables the comparison of the simulated young contrail coverage with the observed regional coverage due to line shaped contrails.

\subsection{Parameterization of Ice Supersaturation}

[12] Contrail cirrus coverage is limited by a potential coverage, the fractional cloud free supersaturated area, the definition of which we recall from Burkhardt et al. [2008]. Figure 1 shows the dependency of the model's natural cloud coverage, $b_{c i}$, as diagnosed from the grid mean relative humidity, $r$ [Sundqvist, 1978]. This relationship is based on the assumption of a uniform subgrid-scale variability of humidity. Natural clouds start to be present in the model's grid box at a critical relative humidity, $r_{c i}$, which is nearly constant in the upper troposphere. Whereas natural cirrus develop at substantial ice supersaturations, contrails can form and persist already in saturated air. Therefore the critical value for cirrus formation, $r_{c i}$, is larger than the critical value, $r_{c c}$, at which a part of the model grid box is at least ice saturated. This critical value, $r_{c c}$, is derived from $r_{c i}$ assuming natural cirrus forms via homogeneous freezing of supercooled liquid aerosol particles and is therefore dependent on temperature.

[13] The fractional cloud-free ice supersaturated area in a grid cell, $B_{c c}$, is parameterized in ECHAM4 using the same assumptions of the subgrid-scale variability of the moisture field as is underlying the natural cloud coverage $b_{c i}$ (Figure 1) and using the critical value $r_{c c}$. It was shown by Burkhardt et al. [2008] that average supersaturation frequencies as simulated by the ECHAM4 model lay in the extratropics within the range of values obtained from aircraft in situ measurements, MOZAIC (Measurements of ozone and water vapor by Airbus in-service aircraft) [Gierens et al., 1999b] and spaceborne remote sensing, AIRS (Atmospheric Infrared Sounder) [Gettelman et al., 2006] except in winter when supersaturation frequency is underestimated by about $20 \%$ as compared to AIRS. In the tropics, an area in which AIRS and MOZAIC estimates strongly disagree on the frequency of ice supersaturation (AIRS estimates are 4 times smaller than MOZAIC estimates), annual average frequencies were overestimated by about $50 \%$ compared to MOZAIC data when assuming that $23 \%$ of supersaturation events detected in the MOZAIC data were actually in cloud measurements and when assuming that MOZAIC supersaturation estimates are representative for the whole of the tropics even though sampling is sparse and seasonally varying. Absolute values of inferred supersaturation from AIRS are regarded highly uncertain and suffer from coarse vertical resolution. Nevertheless, the agreement in the spatial patterns of simulated and AIRS supersaturation is very encouraging. Given the above observational issues the parameterization of supersaturation is judged to perform well [Burkhardt et al., 2008]. Actual 
contrail cirrus coverage, $b$, is, in equation (1), limited to the potential contrail cirrus coverage, $B_{c c}$.

[14] Persistent contrails form when air is supersaturated and sufficiently cold. Therefore the area in which persistent contrails form (potential contrail coverage, not shown), $B_{c o}$, is a subdomain of the potential contrail cirrus coverage $B_{c c}$. $B_{c o}$ is only used for the initialization of new contrails and is zero when contrail formation criteria are not fulfilled. When air temperature is well below the contrail formation threshold temperature (see section 2.3) both potential coverages are equal.

\subsection{Contrail Formation and Dissipation}

[15] Contrail formation is parameterized using the thermodynamic Schmidt-Appleman criterion [Schumann, 1996]. Contrails form if a temperature and humidity threshold is exceeded. The formation criterion depends, apart from the surrounding temperature, humidity and pressure, on the water vapor emission index, the specific combustion heat and the overall propulsion efficiency [Schumann, 2000] and has been verified by in situ measurements [Kärcher et al., 1998]. Contrails form in a cloud free area, $B_{c o}$, in which the temperature threshold is exceeded and the relative humidity exceeds a threshold, $r_{c o}$, as long as this area is not already completely covered by contrail cirrus $(b<$ $\left.B_{c c}\right)$. The humidity threshold $r_{c o}$ is inferred from the supersaturation threshold $r_{c c}$ and the Schmidt-Appleman criterion [Burkhardt et al., 2008].

[16] Contrails are initialized with a width $\mathrm{W}_{0}=100 \mathrm{~m}$. The thickness of the contrail is in the first time step a quarter of the thickness of a model level $(\sim 175 \mathrm{~m}$ at about $250 \mathrm{hPa}$ in our model). The thickness of the contrail is assumed to increase subsequently to the full model level thickness. These initial values are typical for contrails during the vortex phase [Sussmann and Gierens, 2001]. The thickness of the newly formed and the older contrails are also consistent with lidar measurements [Freudenthaler et al., 1995]. The latter study motivated a sensitivity experiment (section 4) for which contrails were initialized with a width $\mathrm{W}_{0}=200 \mathrm{~m}$, a value that may be typical for $15 \mathrm{~min}$ old contrails. The newly formed contrails contribute to the overall contrail cirrus coverage:

$$
b_{\text {new }}=\frac{\mathrm{W}_{0} \cdot \mathrm{L}_{\text {new }}}{\mathrm{A}}, \quad \mathrm{L}_{\text {new }}=\mathrm{D}\left(1-\frac{b}{B_{c c}}\right) B_{c o}
$$

with $\mathrm{L}_{\text {new }}$ indicating the portion of the aggregated distance, D, flown per model grid box and time step that develops contrails and A indicating the model's grid box area. The aggregated flight distance per grid box and time interval, D, is prescribed by the AERO2k flight inventory. The term ( $1-$ $\left.b / B_{c c}\right)$ constrains the newly formed contrail coverage and length to the grid box area that is free of preexisting contrail cirrus and natural cirrus assuming a random overlap between new contrails and preexisting contrail cirrus and natural cirrus.

[17] From the total water vapor mass mixing ratio, emitted on all flight legs within a grid box and a time interval, according to AERO2k, M, a portion is attributed to the contrail cirrus ice mass mixing ratio

$$
m_{\text {new }}=\frac{\mathrm{L}_{\text {new }}}{\mathrm{D}} \mathrm{M}
$$

This implies that young contrails start with a typical IWC of $\sim 0.4 \mathrm{mg} / \mathrm{m}^{3}$, a value within the range predicted by large eddy simulations [Lewellen and Lewellen, 2001] and in the lower range of values observed in situ in the contrail near field [Schröder et al., 2000].

\subsection{Spreading}

[18] Contrails spread horizontally due to wind shear and turbulent diffusion. After the dissipation of aircraft wake turbulence the effect of the vertical shear of the horizontal wind dominates the horizontal spreading of the contrails [Dürbeck and Gerz, 1996]. The vertical extent of contrails changes due to turbulent diffusion, due to the shear induced deformation and due to sedimentation of ice crystals. Furthermore, the extent is limited by the extent of the supersaturated layer in which contrails evolve. Since the upper troposphere is usually weakly turbulent, diffusion alone can only explain a small fraction of the observed contrail thicknesses as measured, e.g., by Freudenthaler et al. [1995] and modeled by large eddy simulation [Jensen et $a l ., 1998]$ indicating that the major vertical growth process is sedimentation. The surrounding supersaturation influences sedimentation of ice particles and therefore controls contrail thickness and the spreading rate.

[19] Contrail cirrus spreads in the presence of a vertically sheared horizontal wind field due to their vertical extent. Defining a vertical wind shear vector, $(\partial u / \partial z, \partial v / \partial z)$, spreading of contrail cirrus coverage is proportional to the magnitude of the vertical wind shear vector, to the length, L, and thickness, $\mathrm{H}$, of contrail cirrus:

$$
\left(\frac{\partial b}{\partial t}\right)_{\mathrm{spr}}=\frac{\partial W}{\partial t} \cdot \frac{\mathrm{L}}{\mathrm{A}}=c \sqrt{\left(\frac{\partial u}{\partial z}\right)^{2}+\left(\frac{\partial v}{\partial z}\right)^{2}} \frac{\mathrm{H} \cdot \mathrm{L}}{\mathrm{A}}
$$

assuming that spreading effects only the average contrail width, W, but not L. The thickness of the contrail $1 \mathrm{~h}$ after initialization, $\mathrm{H}$, is set to the model layer thickness, i.e., $\sim 700 \mathrm{~m}$, a value that is consistent with measurements of older contrails [Freudenthaler et al., 1995]. Thickness in nature is often limited by the supersaturated layer thickness which is on average of the same order of magnitude [Spichtinger et al., 2003; Rädel and Shine, 2007]. The spreading constant $c$ depends on the angle of the vertical wind shear vector with the flight direction, the representativity of the resolved magnitude of the wind shear vector and the surrounding humidity due to its influence on $\mathrm{H}$.

[20] Applying equation (6) to a single contrail, $c$ was constrained using observational data. Average spreading rates of the width of an individual contrail, $\partial \mathrm{W} / \partial \mathrm{t}$, associated magnitude of the average wind shear and contrail thickness, H, have been inferred from lidar measurements of young contrails [Freudenthaler et al., 1995]. Using those values we find $c \simeq 0.72$. In the lidar measurements contrails were presumably randomly oriented relative to the shear vector, an assumption that is also made in the climate 

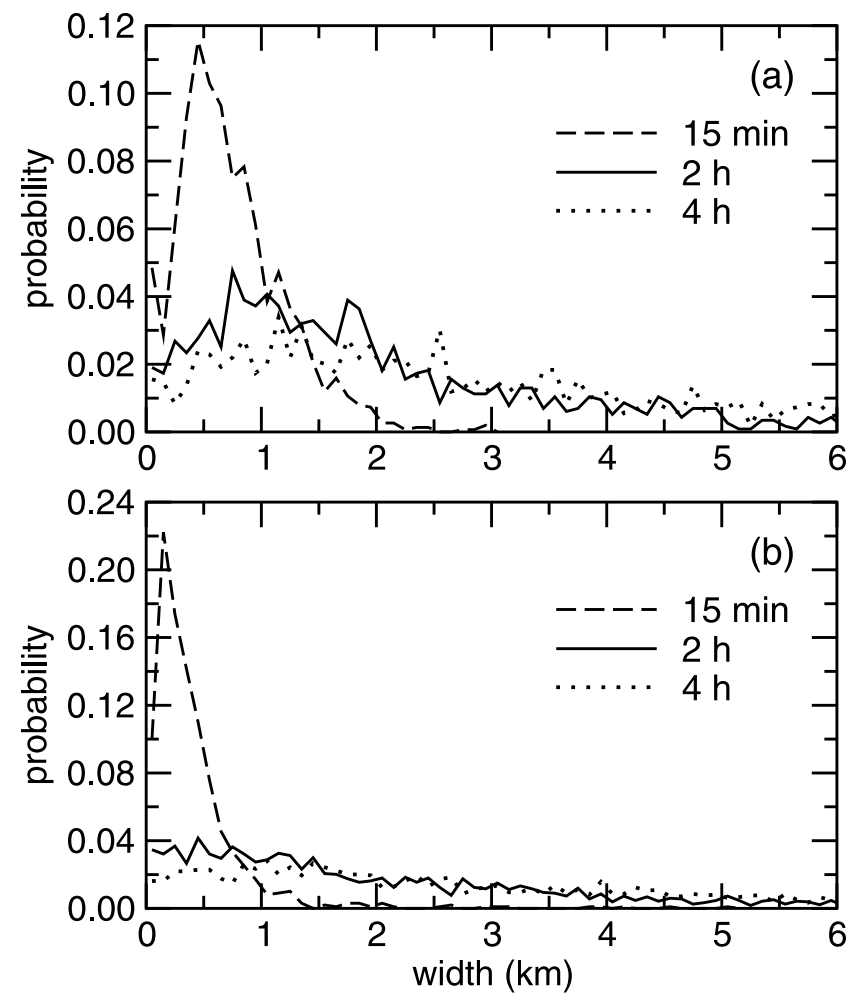

Figure 2. Probability of occurrence of contrail cirrus width over (a) Europe and (b) Thailand after $15 \mathrm{~min}$ (dashed curve), $2 \mathrm{~h}$ (solid) and $4 \mathrm{~h}$ (dotted) at $250 \mathrm{hPa}$.

model. Taking also into account a slight underestimation of the magnitude of the vertical wind shear vector by the largescale model, the spreading constant was estimated to be $c \simeq$ 1.0. In section 4, we will study the sensitivity of our simulations to the uncertainty in the spreading constant. A typical uncertainty connected with the estimate of $c$ may be given by the difference between assuming an angle of $90^{\circ}$ and a random angle between the vertical wind shear vector and the contrail axis. Therefore, in a sensitivity experiment $c$ was reduced by a factor $2 / 3$ [Unterstrasser, 2008].

[21] The average width of contrails within a grid box, $\mathrm{W}=$ $b \cdot \mathrm{A} / \mathrm{L}$, depends mainly on the history of vertical wind shear the contrails experience and on the extent of the supersaturated but cloud free area. Therefore, contrails of a certain age can have a whole range of different widths. Figure 2a shows the probability distribution functions (PDFs) of contrail cirrus width simulated by the ECHAM4 GCM over Europe $15 \mathrm{~min}, 2 \mathrm{~h}$ and $4 \mathrm{~h}$ after contrail formation for an arbitrary August at $250 \mathrm{hPa}$. Fifteen minutes after formation, contrails over Europe are most likely to have widths of $\sim 250 \mathrm{~m}$ to $1 \mathrm{~km}$. The lidar measurements of contrail spreading over southern Germany, performed at favorable moisture conditions (V. Freudenthaler, personal communication, 2006), resulted in estimated contrail widths after $15 \mathrm{~min}$ between $400 \mathrm{~m}$ and $2.2 \mathrm{~km}$, with the most likely value of just below $1 \mathrm{~km}$ [Freudenthaler et al., 1995]. These values lie within the range of widths reproduced by the GCM.

[22] The PDF of contrail width depends mainly on the shear and can therefore be different for different geographical locations. Duda et al. [2004] analyzed contrail widths from spaceborne observations (Geostationary Operational Environmental Satellites, GOES) over the Great Lakes at a time of a major contrail outbreak. After $2.25 \mathrm{~h}$ contrails were approximately $6 \mathrm{~km}$ and after $3.75 \mathrm{~h}$ they were $10 \mathrm{~km}$ wide. Judging from our simulation these large widths occur relatively seldom. Even after $4 \mathrm{~h}$ contrails with widths of around $10 \mathrm{~km}$ can seldom be found. A distribution of young line shaped contrail widths inferred from Landsat imagery over another midlatitudinal site indicates that contrails much wider than $3 \mathrm{~km}$ were seldom observed [Detwiler and Pratt, 1984]. The largest widths inferred visually from Landsat images are $\sim 14 \mathrm{~km}$. The age of those contrails is unknown so that a direct comparison with Figure 2a is not possible.

[23] As a second example we show the simulated width statistic over Thailand. Supersaturation frequency is lower in the tropics than in the extratropics. Wind shear in the extratropics is dominated by speed shear associated with the jet streams whereas in the tropics wind shear is largely due to directional shear fluctuating on short timescales. Moreover, Thailand is one of the few locations over which contrail coverage has been studied. Figure $2 b$ shows the PDF over Thailand, where a larger (smaller) fraction of contrail cirrus has a width $\leq 500 \mathrm{~m}$ (between $500 \mathrm{~m}$ and $2 \mathrm{~km}$ ) after $15 \mathrm{~min}$ and $2 \mathrm{~h}$ than over Europe. Nevertheless, the probability of finding contrails with widths of more than $2 \mathrm{~km}$ appears to be similar over Thailand and over Europe.

\subsection{Ice Water Content}

[24] Deposition/sublimation and precipitation rates, as well as optical properties including optical depth (parameterized as a function of IWC), are formulated for contrail cirrus in the same way as for natural clouds [Roeckner et al., 1996]. The net saturation excess inside a cloud/contrail arising from transport of moisture or cooling of air is converted into ice water, any saturation deficit inside a cloud/contrail leads to sublimation of cloud ice to restore saturated conditions. This means that natural cirrus and contrail cirrus compete for the saturation excess. Sublimation of the total water content of a cloud/contrail leads to the dissipation of the cloud/contrail. The ice particle precipitation rate is formulated as a divergence of the sedimentation mass flux. Precipitation falling into a cloud-free grid box may sublimate according to the saturation deficit there or melt when encountering the freezing level.

[25] Introducing the contrail cirrus ice water mixing ratio variable requires slight changes in the standard model equations for the water vapor mixing ratio and for cloud water mixing ratio. The contrail cirrus ice water content is associated with the contrail cirrus coverage and transported only into areas covered by contrail cirrus, while cloud water is transported only into areas free of contrail cirrus. Deposition (sublimation) within the contrail cirrus is a sink (source) of water vapor and sublimating sedimenting contrail cirrus ice is a source.

[26] In Figure 3a the zonally averaged annual mean contrail cirrus ice water content as simulated by the contrail cirrus module in the ECHAM4 climate model is shown. Mean IWC is largest between $300 \mathrm{hPa}$ and $400 \mathrm{hPa}$ and between $30^{\circ} \mathrm{N}$ and $50^{\circ} \mathrm{N}$ reaching values of up to $10 \mathrm{mg} / \mathrm{m}^{3}$. The IWC is larger in regions where air contains more water vapor available for deposition. IWC decreases toward the 

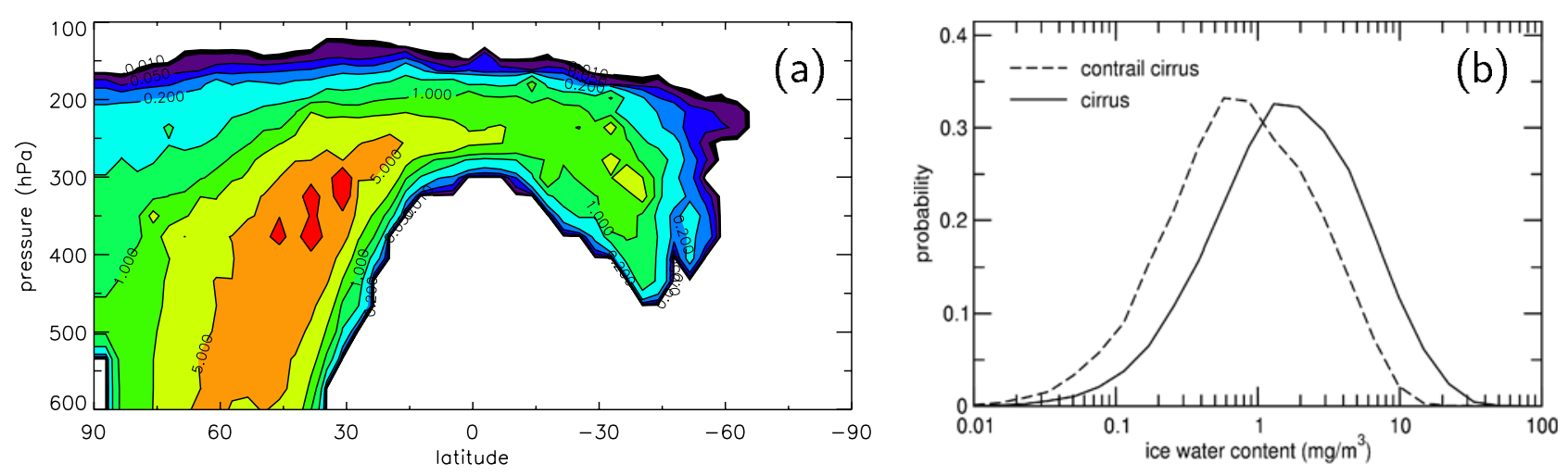

Figure 3. (a) Zonally averaged annual mean contrail cirrus ice water content (isolines at $0.01,0.02$, $0.05,0.1,0.2,0.5,1,2,5,10 \mathrm{mg} / \mathrm{m}^{3}$ ) and (b) probability of occurrence of ice water content in contrail cirrus (dashed curve) and in natural cirrus (solid) over western Europe and part of the North Atlantic at temperatures between $210 \mathrm{~K}$ and $240 \mathrm{~K}$ and pressures of $220 \mathrm{hPa}$ and $350 \mathrm{hPa}$ for 15 autumn months.

tropopause. The maximum in IWC is situated below the altitude of largest air traffic density at $\sim 250 \mathrm{hPa}$. Note that in areas where contrails only exist infrequently, e.g., the Southern Hemisphere and at low altitudes, our estimates of IWC are based on only few events. In summer contrails do not often persist below the $500 \mathrm{hPa}$ level and have in the midlatitudes on average an IWC larger than $1 \mathrm{mg} / \mathrm{m}^{3}$ between $450 \mathrm{hPa}$ and $250 \mathrm{hPa}$. In winter contrails can also persist in the extratropics at lower altitudes (below the $600 \mathrm{hPa}$ level). In the midlatitudes they attain large IWC exceeding $5 \mathrm{mg} / \mathrm{m}^{3}$ over a large altitude band.

[27] In Figure 3b PDFs of ice water content of contrail cirrus and natural cirrus as simulated in ECHAM4 are shown over western Europe and parts of the North Atlantic flight corridor for temperatures $210-240 \mathrm{~K}$ and pressures $220-350 \mathrm{hPa}$. The selected area and season corresponds to the region probed during the Interhemispheric Differences in Cirrus Properties from Anthropogenic Emissions (INCA) aircraft campaign [Gayet et al., 2004]. The shape of the PDFs of simulated natural cirrus and simulated contrail cirrus are very similar, presumably because the same source and sink processes act on the ice water content of both cloud types. The range of values measured during INCA is within the spread of the simulated cirrus PDF, but the simulated cirrus mean IWC is somewhat lower than indicated by the observations $(25 \%-75 \%$ percentiles range between $2.7-$ $18 \mathrm{mg} / \mathrm{m}^{3}$ with a median value of $8 \mathrm{mg} / \mathrm{m}^{3}$ ) [Gayet et al., 2004]. Those values are consistent with the compilation of IWC measurements from numerous field campaigns [Schiller et al., 2008]. However, airborne sampling may be biased to thicker cirrus clouds that are more easily detectable and therefore probed. On the other hand, the model may underestimate the IWC of cirrus [Lohmann et al., 2007].

[28] The parameterization predicts contrail cirrus with a somewhat lower mean IWC than that of natural clouds. Ice water contents in young contrails have been measured in situ at temperatures near $218 \mathrm{~K}$, indicating a range 2$6 \mathrm{mg} / \mathrm{m}^{3}$ [Spinhirne et al., 1998; Schröder et al., 2000; Febvre et al., 2009], values that are included in the simulated PDF. Again, measurements of IWCs may be biased toward high values, because only clearly visible contrails have been probed. At any rate, the lack of
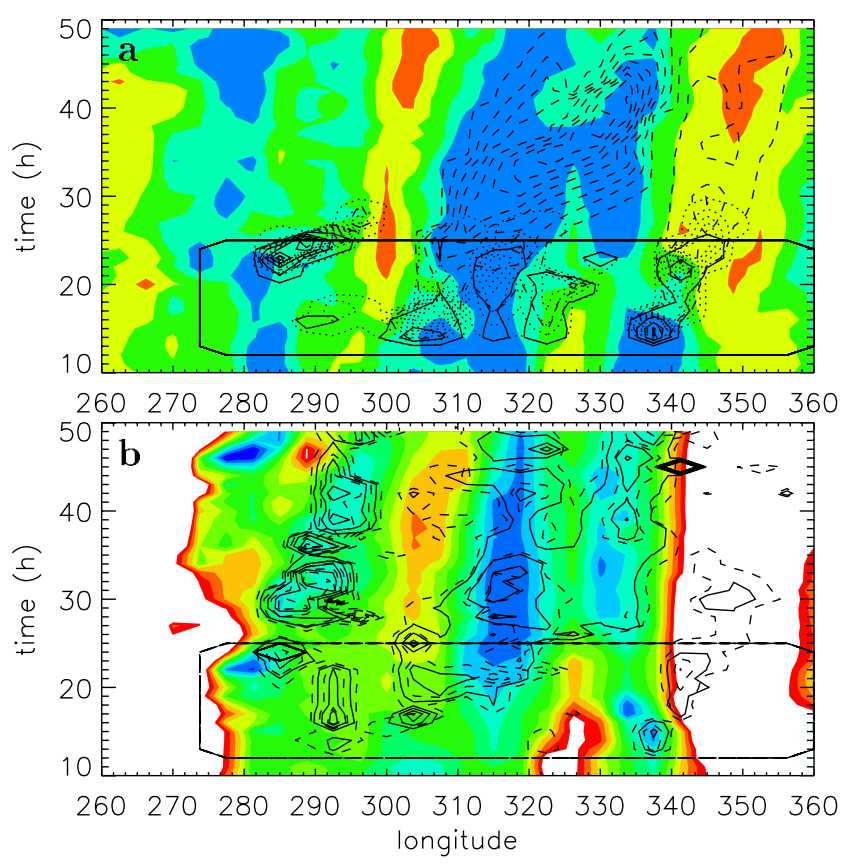

Figure 4. Hovmoeller diagram of (a) potential contrail cirrus coverage (color, blue indicating large values and red indicating low values), coverage due to $15 \mathrm{~min}$ old (solid contours), due to young (up to $4 \mathrm{~h}$ old) (dotted) and due to contrail cirrus of any age (dashed) and (b) saturation excess (color, blue indicating large values and red and white indicating low values), specific ice mass mixing ratio (solid) and deposition of water vapor on ice particles per model time step in contrails (dashed). The box indicates the time and longitude of air traffic. Fields are averaged between $35^{\circ} \mathrm{N}$ and $65^{\circ} \mathrm{N}$. Absolute values are not given because they are not representative for the contrails or their immediate surroundings. Coverage due to $15 \mathrm{~min}$ old and due to young contrails is multiplied by 10 compared to coverage due to contrail cirrus of any age. All isolines are equidistant. 

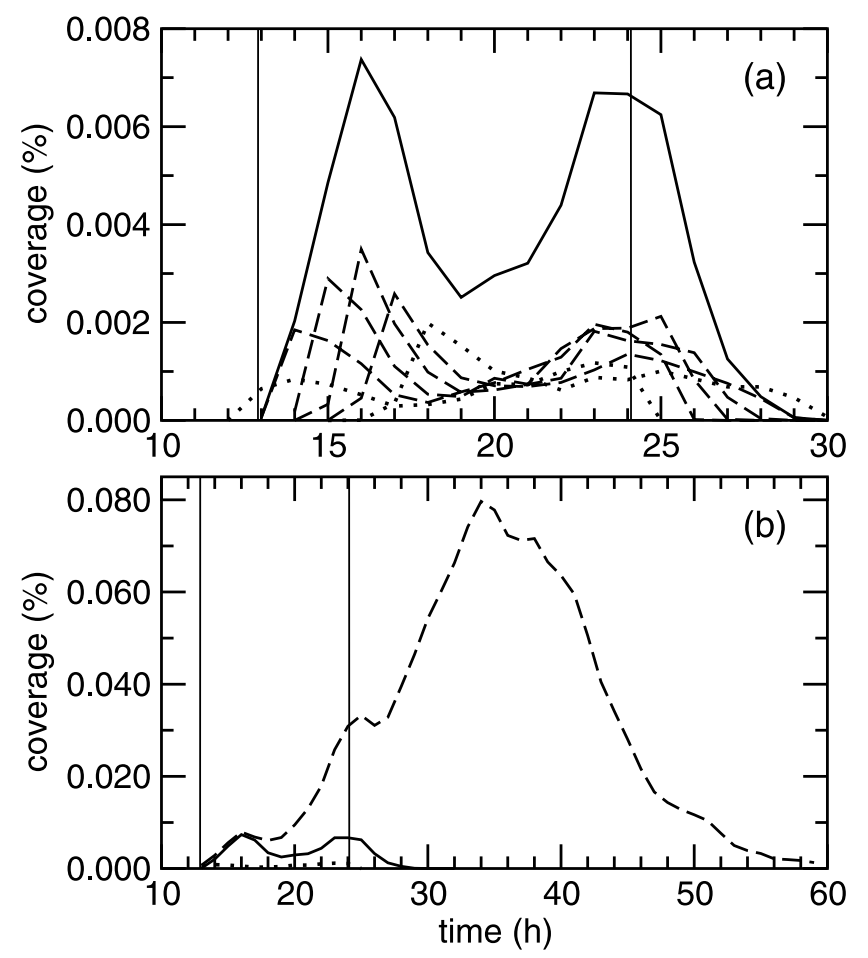

Figure 5. Time series of coverage (a) due to $15 \mathrm{~min}$ old (dotted curve), 1, 2, 3, $4 \mathrm{~h}$ old (dashed) and $5 \mathrm{~h}$ old (dotted) contrails and due to young contrails (sum of coverages of contrails that are between 1 and $4 \mathrm{~h}$ old) (solid) and (b) due to $15 \mathrm{~min}$ old (dotted), due to young contrails (between 1 and $4 \mathrm{~h}$ ) (solid) and due to contrail cirrus of any age (dashed). Coverages are averaged over all longitudes within the latitude band $35^{\circ} \mathrm{N}$ to $65^{\circ} \mathrm{N}$. Vertical lines indicate the time period of air traffic.

measurements of IWC in contrail cirrus does not allow a final conclusion to be drawn.

\section{Idealized Experiment}

[29] The performance of the contrail cirrus parameterization has been tested prescribing cross Atlantic air traffic along a connection line between Europe and the U.S.A. on a constant pressure level $(250 \mathrm{hPa})$ for $12 \mathrm{~h}$. This ensures that different synoptic situations are sampled. Each model grid box was traversed once at each time step. Figure $4 \mathrm{a}$ shows the time development and eastward propagation of potential contrail cirrus coverage, and contrail and contrail cirrus coverage associated with the prescribed air traffic. Figure $4 \mathrm{~b}$ shows the saturation excess, ice mass mixing ratio and water vapor deposition per model time step in the contrail cirrus clouds. The data have been averaged between $35^{\circ} \mathrm{N}$ and $65^{\circ} \mathrm{N}$. The choice of such a large latitudinal band ensures that the contrail cirrus is not advected out of the analyzed area. Note that due to the averaging over a large latitudinal belt, absolute values are not shown because they are not representing local conditions but instead indicate the large-scale situation.

[30] Within the $12 \mathrm{~h}$ of cross Atlantic air traffic there are several occasions when contrails form in areas of high potential contrail cirrus coverage. They are advected east- ward, spread and water vapor is deposited. The degree of spreading, the lifetime of the individual contrail cirrus and their ice mass mixing ratio are very much dependent on atmospheric conditions in the analyzed area. The coverage due to most of the contrails declines after only a few hours but remnants of the contrails can exist longer in which water vapor is deposited. Only on one occasion $\left(305^{\circ} \mathrm{E}\right.$ and $\sim 2 \mathrm{~h}$ after the start of air traffic) contrails spread considerably. This contrail outbreak happens at a time and in an area where the potential contrail cirrus coverage is large and where water vapor available for deposition is abundant. Further west, near $285^{\circ} \mathrm{E}$ and close to the end of the time interval of air traffic, contrail cirrus coverage grows slowly in an area and at a time of relatively low potential contrail cirrus coverage and of relatively large amounts of available water vapor. The resulting contrail cirrus has a high ice mass mixing ratio but does not cover a large area (the corresponding coverage is lower than the first isoline and therefore not indicated in Figure 4a). Around $340^{\circ} \mathrm{E}$ contrails develop that grow slowly and gain ice mass in a latitudinally inhomogeneous area.

[31] Figure 5a shows how the newly initiated contrails spread during the first $5 \mathrm{~h}$ of their lifetime. Contrail coverage initiated at $\sim 13 \mathrm{~h}$ and approximately $305^{\circ} \mathrm{E}$, $322^{\circ} \mathrm{E}$ and $338^{\circ} \mathrm{E}$ (Figure 4a) increases on average during the first $3 \mathrm{~h}$ of the contrail lifetime. Later the coverage due to those newly initiated contrails shrinks. The second peak of young contrail development happens toward the end of the time series shortly after $20 \mathrm{~h}$ at about $285^{\circ} \mathrm{E}, 315^{\circ} \mathrm{E}$ and $342^{\circ} \mathrm{E}$ (Figure $4 \mathrm{a}$ ). Coverage appears to grow during the first $2 \mathrm{~h}$ and then decays slowly. Figure $5 \mathrm{~b}$ shows that contrail cirrus coverage is increasing dramatically after air traffic has already ceased, reaching a maximum in coverage at $\sim 34 \mathrm{~h}$, about $9 \mathrm{~h}$ after the end of air traffic. Contrail cirrus coverage subsequently decreases rapidly and approaches zero about $30 \mathrm{~h}$ after air traffic terminates. The contrails that were formed over the western part of the Atlantic do not reach Europe but decay over the eastern part of the Atlantic.

[32] The overall contrail cirrus coverage is mainly determined by the large contrail outbreak (Figure 5b) indicating that the monthly variability of contrail cirrus coverage may be large since it is influenced by few single events. In comparison, the old parameterization of Ponater et al. [2002] simply scaled all newly formed contrails equally in order to obtain an estimate of line shaped contrail coverage. Our parameterization suggests that contrail cirrus coverage should not be calculated by scaling the frequency of contrail formation because coverage scales more strongly with ice supersaturation.

\section{Contrail Coverage due to Global Air Traffic}

[33] In this section, simulated contrail coverage due to global air traffic shall be described and compared to observational data. A 10 year simulation of contrail cirrus was performed using the global air traffic inventory AERO2k for the year 2002 [Eyers et al., 2004]. Coverage due to young contrails, that were tracked independently (section 2.1), was calculated and compared to observations of line shaped contrail coverage inferred from satellite data. For the comparison the sensitivity of the resulting coverage to uncertainties in physical parameters, initial width and 

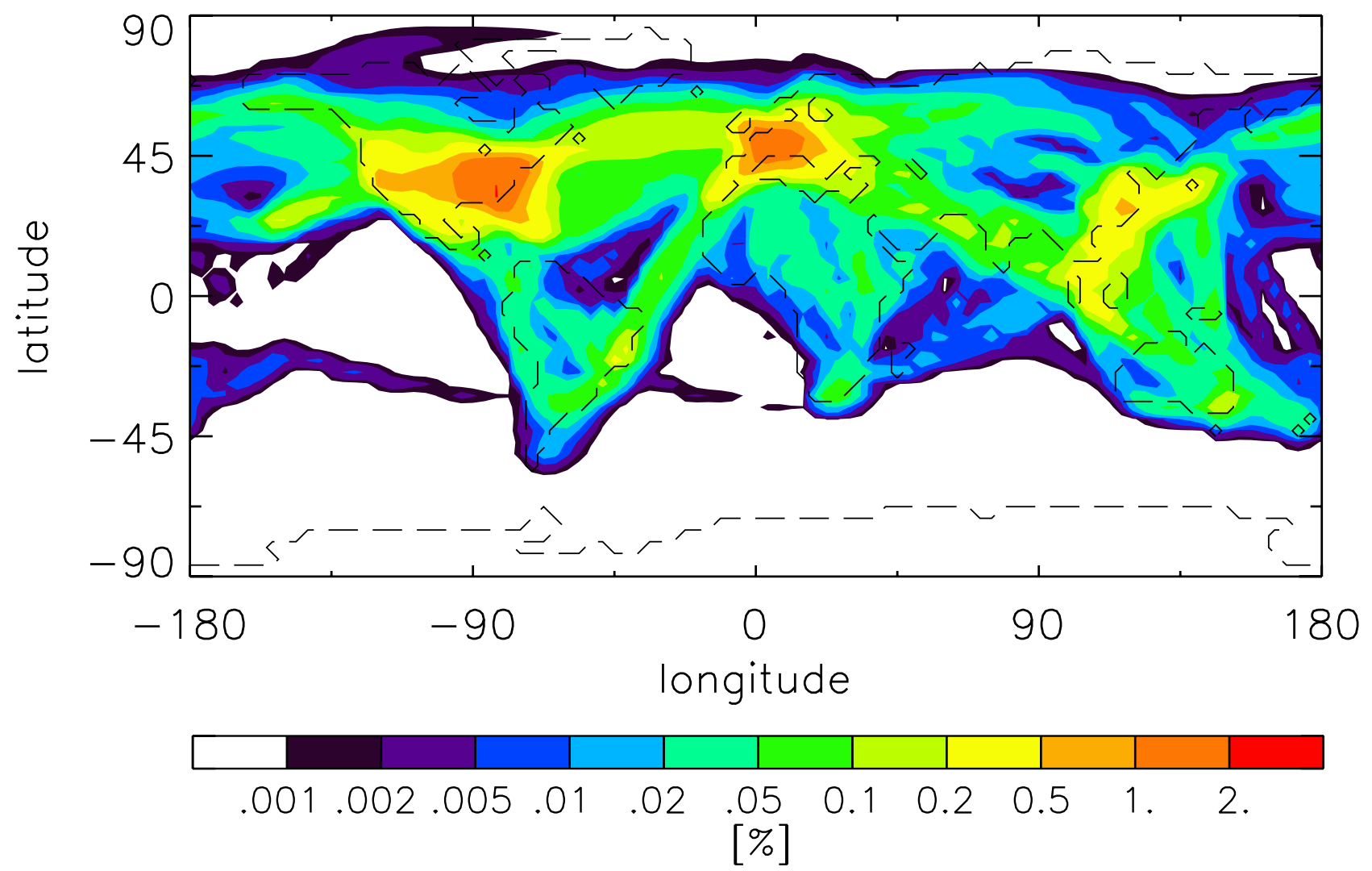

Figure 6. Simulated annual mean coverage due to visible young contrails (optical depth $>0.02$, age $\leq 5 \mathrm{~h}$ ).

spreading constant (sections 2.3 and 2.4, respectively), and in parameters crucial only for validational purposes, optical depth and age threshold, were taken into account.

[34] Simulated contrail cirrus were assumed to be line shaped when they were up to $5 \mathrm{~h}$ old. Theoretically the length of time for which contrails remain line shaped is not directly related to their age but to the level of turbulence the contrails experience, a quantity that is usually not well represented in climate models. We compare observed line shaped contrails with simulated young contrails, since they are less likely to have experienced atmospheric perturbations that would have made them lose their line shape. This age threshold is uncertain and is likely to vary regionally and temporally. In order to determine the sensitivity to this threshold, an age threshold of $4 \mathrm{~h}$ was also used.

[35] Contrail detection in satellite images has been studied using one automated detection algorithm [Mannstein et $a l ., 1999]$ that identifies linear structures in clouds. Contrail detection depends mainly on the optical depth and the size of the contrails, but also on a number of other variables determining the contrast between the brightness temperature of the contrail and the surrounding. The dependence of the detection efficiency of contrails on those variables is not known. The threshold for the visual detection of thin cirrus has been estimated to be 0.01-0.03 [Sassen and Cho, 1992]. It has been assumed in the literature that in spaceborne passive remote sensing contrails can be detected that have an optical depth at wavelengths in the visible part of the spectrum of 0.02 and more [Ponater et al., 2002; Marquart, 2003]. This is likely an underestimation of the true detection threshold. Therefore, we will use this value but also analyze the sensitivity of our results to the assumption of a higher threshold.

[36] When comparing model estimates to regional observations, a number of problems should be kept in mind. Estimates of contrail coverage exist only for very limited time periods and therefore do not represent climatological values. The performance of the contrail detection algorithm and therefore the estimated line shaped contrail coverage is strongly dependent on the specific Advanced Very High Resolution Radiometer (AVHRR) instrument and on the tuning of free parameters in the detection algorithm [Meyer et al., 2002]. In some studies the algorithm has been tuned to result in very few false identifications [Meyer et al., 2002, 2007]. In others the estimates are corrected by comparing automated contrail detection to subjective contrail detection for a few days and then assuming that the error is constant in time [Palikonda et al., 2005; Minnis et al., 2005]. The two latter studies are also subject to a diurnal correction taking into account the time of day of contrail detection and the diurnal variation in air traffic, whereas Meyer et al. [2002] inferred day and nighttime coverage. Because of those varying approaches, regional estimates of contrail coverage obtained from different studies are not easily intercomparable. Finally, the flight movement data set, used in this study, is inferred over Europe, the North Atlantic and North America from actual flight movements as detected by the radar network. In other areas, it consists only of scheduled flights assuming planes take routes of minimum distance. Observations also include contrails produced by 


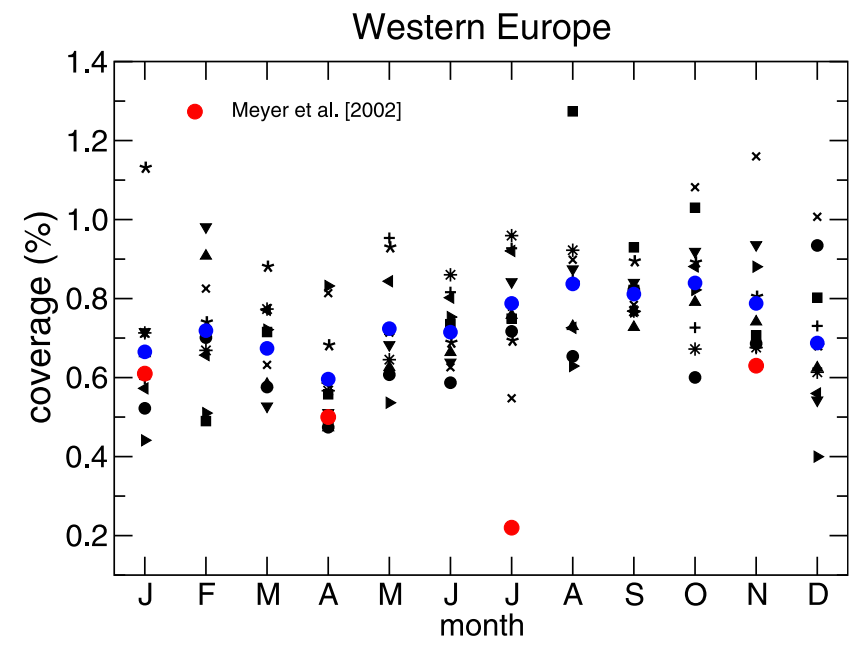

Figure 7. Average seasonal cycle of coverage due to visible young contrails over Europe (blue), 10 different realizations of the seasonal cycle (black) and line shaped contrail coverage inferred from satellite observations (red). Different black symbols indicate values for different years.

nonscheduled civil flights and military planes. Military air traffic is estimated to add on average about $10 \%$ to the existing global air traffic.

\subsection{Global Distribution}

[37] Figure 6 shows the global distribution of the annually averaged coverage due to young $(\leq 5 \mathrm{~h})$ contrails that have at least a visible optical depth of 0.02 and assuming a random overlap. The largest coverage due to visible young contrails can be found over the main traffic areas of Europe and North America and a smaller local maximum over the east coast of Asia between Japan and Indonesia. Over North America maximum coverage approaches or exceeds locally $2 \%$, roughly consistent with satellite observations [Palikonda et al., 2005].

[38] Our simulated coverage is not limited to flight corridors since contrails can be advected into air traffic free zones. Therefore maxima of contrail coverage are smoothed out compared to the old line shaped contrail parameterization [Marquart et al., 2003, Figure 2]. In the tropics contrail coverage is larger in the new than in the old parameterization. This is probably due to corrections in the parameterization of potential contrail and contrail cirrus coverage introduced by Burkhardt et al. [2008], allowing a higher contrail cirrus coverage at high relative humidity than before. A higher coverage in the tropics may also be caused by an increase in flight movements in the AERO2k inventory relative to the inventory for 1992 used by Ponater et al. [2002] and Marquart et al. [2003]. A large fraction of simulated contrails are subvisible ( $\sim 60 \%$ over Europe, $\sim 50 \%$ over the U.S.A., $\sim 35 \%$ over Japan and $\sim 25 \%$ over Thailand). This fraction is significantly larger in the extratropics (by $10-15 \%$ ) than using the old parameterization [Marquart, 2003]. Even though over Europe and the U.S.A. our estimate of visible young contrail coverage is on average smaller, coverage due to young contrails of any optical depth is larger than suggested using the old parameterization.
[39] Global coverage due to visible line shaped contrails amounts to $0.05 \%$ compared to $0.06 \%$ in the work of Marquart et al. [2003] and to a daytime only coverage of $0.07 \%$ in the work of Ponater et al. [2002]. Changing the age threshold by $\pm 1 \mathrm{~h}$ introduces an uncertainty in the global coverage due to young contrails of $\pm 0.01 \%$. The uncertainty of young contrail coverage due to changes in the spreading constant $(c=2 / 3$ instead of $c=1$, section 2.4 ) is $\pm 0.02 \%$. The uncertainty due to changes in the initial width $\left(\mathrm{W}_{0}=200 \mathrm{~m}\right.$ instead of $\mathrm{W}_{0}=100 \mathrm{~m}$, section 2.3$)$ is an order of magnitude smaller. Assuming an optical depth detection threshold of 0.05 instead of 0.02 , coverage due to young contrails amounts globally to $0.02 \%$. The coverage due to young contrails of any optical depth is $0.1 \%$, the same as in the work of Marquart [2003] whereas Ponater et al. [2002] estimate $0.13 \%$.

\subsection{Interannual Variability}

[40] Contrail cirrus coverage is highly variable from month to month. In Figure 7 the average seasonal cycle and 10 different realizations of the visible young contrail coverage over Europe are shown. The range of coverage for one month can be as large as the mean coverage and is larger than the range spanned by the mean seasonal cycle. Monthly coverages appear to be largely independent from the coverage of the preceding month.

[41] Simulated mean coverage over western Europe agrees well with satellite inferred coverage of line shaped contrails over Europe [Meyer et al., 2002] in so far as the observed coverages lie within the spread of simulated coverages, except in summer when the observed coverage is smaller than any of the model realizations. Annual mean coverage is slightly overestimated even though supersaturation frequency over Europe (and generally over the extratropics) is slightly underestimated when compared to supersaturation as derived from AIRS and MOZAIC [Burkhardt et al., 2008].

[42] A number of reasons may be responsible for the deviations. In particular, observations are averaged over a limited number of overpasses (702 day time and 232 nighttime scenes covering all four seasons) and therefore may not be representative for the particular season. The optical depth threshold for contrail detection by satellites may be larger than the visibility threshold 0.02 , and optical depth threshold and detection efficiency may be varying seasonally as they depend, e.g., on the surface conditions and cloud coverage. The spreading constant or the initial width may be too high. Finally, some of the young contrails may have been in nature already indistinguishable from natural cirrus. In order to illuminate possible reasons for discrepancies between modeled and observed contrail coverage the dependence of simulated contrail coverage on the optical depth and age thresholds, spreading constant and initial width of the contrails is studied in the next section.

\subsection{Comparison With Observations}

[43] The sensitivity of young contrail cirrus coverage to the optical depth threshold, age threshold, the spreading constant and the initial contrail width was calculated. Figure 8 displays observed coverage over several regions and the simulated coverages due to visible, young contrails, where 'young' either means up to 4 or $5 \mathrm{~h}$ old, and 'visible' 


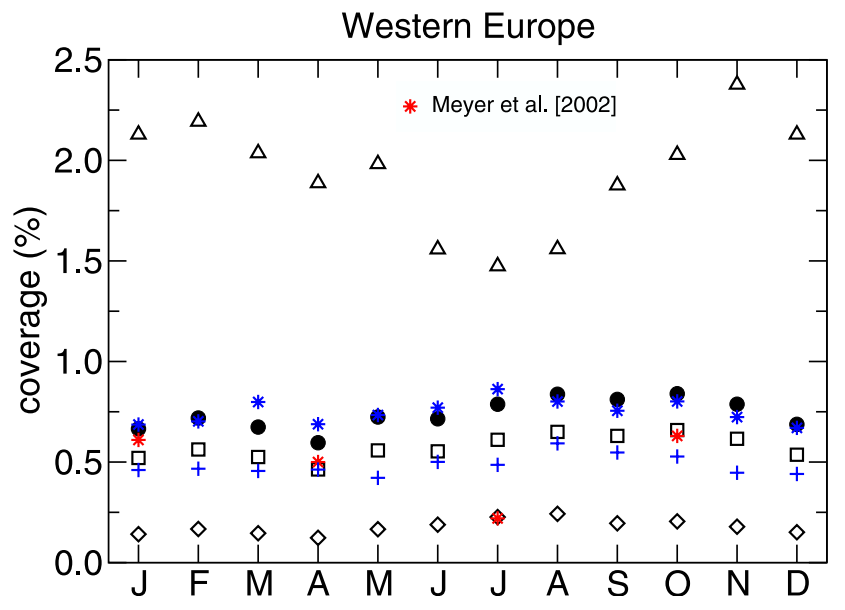

Continental U.S.A.

Eastern North Pacific
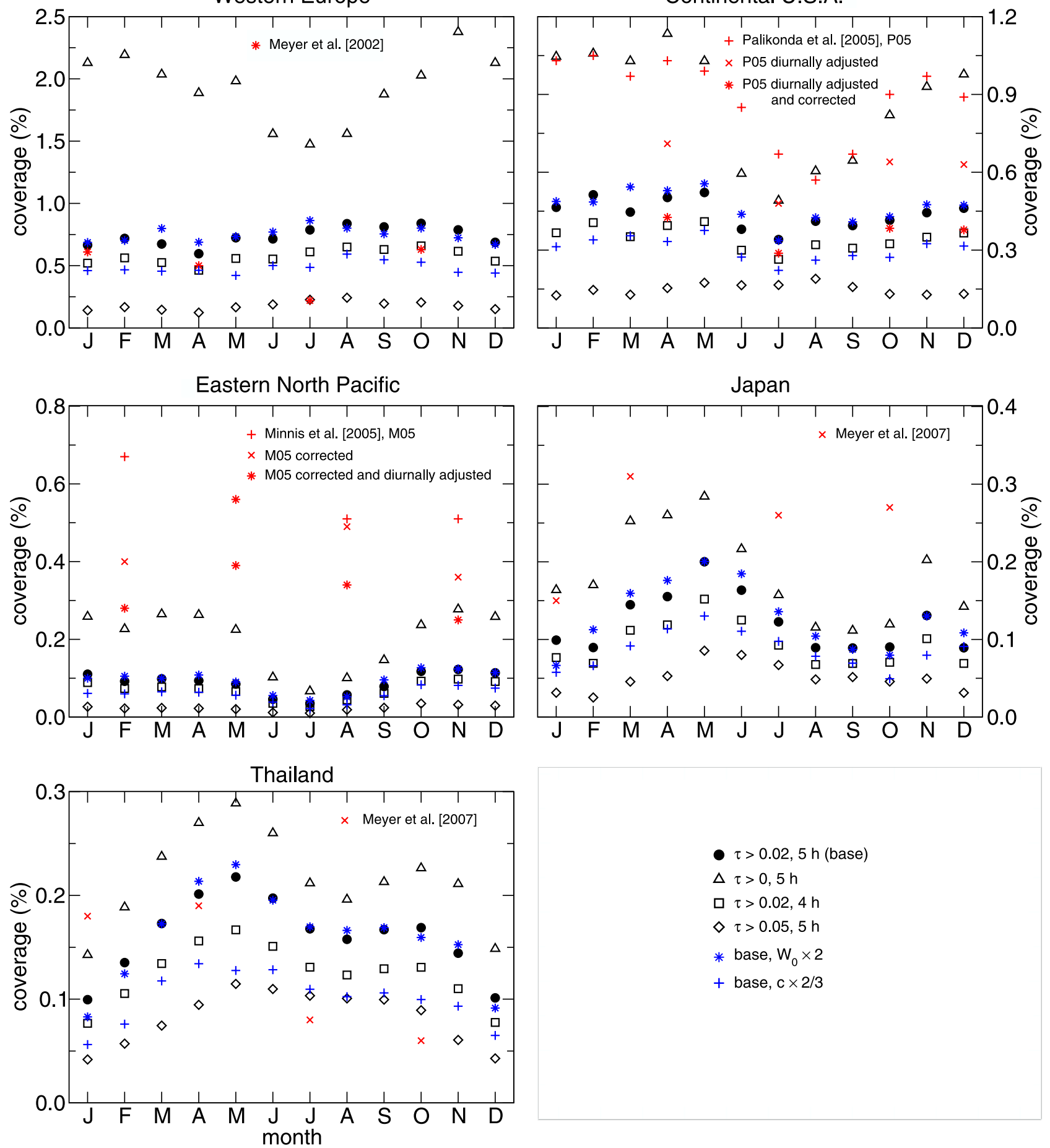

$$
\begin{aligned}
& -\tau>0.02,5 \mathrm{~h} \text { (base) } \\
& \Delta \tau>0,5 \mathrm{~h} \\
& \square \tau>0.02,4 \mathrm{~h} \\
& \diamond \tau>0.05,5 \mathrm{~h} \\
& \text { * base, } \mathrm{W}_{0} \times 2 \\
& + \text { base, } \mathrm{c} \times 2 / 3
\end{aligned}
$$

Figure 8. Average seasonal cycle of coverage due to visible young contrails over different regions and their sensitivity to the spreading constant $(c=1)$, initial contrail width $\left(\mathrm{W}_{0}=100 \mathrm{~m}\right)$, optical depth and age thresholds (symbols are given in the legend) and observations of line shaped contrail coverage as inferred from satellite scenes (red symbols). Note that in the eastern North Pacific in May original (pluses) and corrected (crosses) observed contrail coverage are equal.

is now defined as having an optical depth of at least 0.02 or 0.05 . The spreading constant is 1 or $2 / 3$ and the initial width is $100 \mathrm{~m}$ or $200 \mathrm{~m}$ (sections 2.3 and 2.4). For reference overall contrail cirrus coverage including all young contrail cirrus regardless of their optical depth is also displayed.
[44] The influence of the studied parameters has a varying impact on the contrail coverage in different areas. The optical depth threshold is the most important parameter in all the regions considered here. Over western Europe, the U.S.A. and over the eastern North Pacific the interannual 
variability of the coverage and the sensitivity to the spreading constant and to variations of the age threshold are small compared to the sensitivity to the optical depth threshold. Over Japan and Thailand the sensitivity to the optical depth threshold is reduced so that the interannual variability and the sensitivity to variations in the spreading constant and in the age threshold are of similar importance than the sensitivity to the optical depth threshold. Variations in the initial width of the contrail have in general a minor impact on contrail coverage indicating that the exact choice is of little importance.

[45] Over western Europe contrail coverage is well estimated by the model considering the sensitivity of the coverage to the above parameters. Even in summer, the observed value lies in the range of simulated coverages. The seasonal cycle of simulated contrail coverage depends on the optical depth threshold. In summer potential contrail coverage is smaller than in other months and consequently young contrail coverage (including also optically thin contrails) is lower than in other seasons. On the other hand, more water vapor is available for deposition in the summer months due to the higher temperatures, so that contrails have a higher optical depth. Therefore, the coverage due to contrails that have an optical depth of at least 0.02 or 0.05 is largest in late summer and autumn. Taking into account the uncertainty in contrail coverage due to interannual variability, sensitivity to optical depth and age thresholds and changes in the spreading constant, contrail coverage over Europe is well simulated.

[46] Over the U.S.A. observed contrail coverage obtained by the detection algorithm is much higher than over Europe. A diurnal adjustment has been applied reducing observed contrail coverage considerably [Palikonda et al., 2005]. Observed contrail coverage was further corrected by $40 \%$ as suggested by Palikonda et al. [2005]. The corrected and diurnally adjusted contrail coverage is very well reproduced by the model. The seasonal cycle of observed and simulated contrail coverage also fit extremely well. The summer minimum in coverage is connected with a minimum in supersaturation frequency over the U.S.A. [Gettelman et al., 2006] that is reproduced by the supersaturation parameterization [Burkhardt et al., 2008]. Again, the seasonal cycle of contrail coverage depends on the optical depth threshold. Coverage due to contrail cirrus with optical depth exceeding 0.05 is largest in summer whereas coverage is lowest in summer when lowering the optical depth threshold.

[47] Except over North America, the North Atlantic and Europe the quality of the air traffic data set is low. Instead of radar data of actual flight movements, planned flight schedules together with the assumption of shortest flight routes are used to calculate air traffic movements. In those areas, non time-tabled flights (e.g., military flights), deviations from great circles and holding patterns are not included in the data set resulting in an underestimation of flight movements.

[48] Over the eastern North Pacific contrail coverage was inferred for 4 single months using an automated detection algorithm [Minnis et al., 2005]. The detection error connected with the estimates was determined subjectively by visually inspecting one single day per analyzed month. The estimate of contrail coverage was then corrected assuming the error to be constant for each month. The correction varied between $0-40 \%$ depending on the month and caused a reversal of the seasonal cycle. Simulated contrail coverage over the eastern North Pacific is about a third of the observed corrected and diurnally adjusted coverage. Since the detection efficiency of contrails is larger over the ocean than over land due to the homogeneous background, more optically thin contrails may have contributed to the large observed coverages than over land. Nevertheless, when considering contrails of any optical depth, contrail coverage is still lower than suggested by Minnis et al. [2005]. The disagreement is too large to be explained by the sensitivity to the studied parameters using the above parameter ranges. Assuming that in the eastern North Pacific contrail cirrus stay longer line shaped would lead to larger contrail coverage, but it is not clear why this should be the case. Model fields such as vertical wind shear, water vapor available for deposition and potential contrail cirrus coverage do not seem to be drastically wrong in this area. In particular, the latter two are large enough to support a large coverage of contrail cirrus of any age that exceeds the estimate of observed line shaped contrail coverage in this area by far. The corrections applied to the observations of contrail coverage may be too small. Finally, for the largest part of the Pacific area flight movements are underestimated in the flight inventory. Owing to the assumption that planes fly along great circles, most of the North Pacific air traffic in the AERO2k data set is located north of the eastern North Pacific box as defined by Minnis et al. [2005]. This means that southward shifts of actual versus scheduled flight tracks would increase air traffic and coverage significantly within the analyzed area.

[49] Over Japan and Thailand contrail coverages were inferred for 4 months analyzing a few hundred satellite scenes with the automated detection algorithm [Meyer et al., 2007]. Over Japan, interannual variability is in most months nearly as large as the sensitivity to the optical depth threshold. Linear contrail coverage is underestimated especially in later summer and autumn. The model simulates a maximum in contrail coverage and supersaturation frequency in spring and a minimum from late summer to winter. The low contrail coverage in late summer and autumn is not caused by a low supersaturation frequency. As in the Pacific case, coverage due to contrail cirrus of any age exceeds observed contrail coverage by far, indicating that ice supersaturation frequency and excess water vapor are high enough to support more contrail cirrus. The underestimation may be due to flight activity being underestimated in the AERO2k inventory or to model deficiencies. Over Thailand simulated contrail coverage appears to agree with observations considering the interannual variability and the large sensitivities due to the optical depth and age thresholds and the spreading constant. This is an improvement over the old parameterization that underestimated line shaped contrail coverage over Thailand strongly [Meyer et al., 2007].

\section{Summary and Conclusions}

[50] In this paper we introduce for the first time a processbased prognostic scheme for contrail cirrus. The scheme allows to capture persistence, advection and spreading of contrails. Processes controlling contrail coverage are parameterized and constrained by measurements. The 
scheme's performance is studied in an idealized experiment. Contrail coverage and its sensitivity to variations in the physical parameters of two processes and to parameters governing the comparison between simulated and observed coverage have been analyzed. The performance of the contrail cirrus scheme was assessed using regional observations of line shaped contrail coverage.

[51] Contrail cirrus is introduced as a new cloud class in the ECHAM4 climate model. The treatment of contrail cirrus coverage, contrail length and ice mass mixing ratio is prognostic. Contrail cirrus coverage is restricted to the parameterized fractional supersaturated area. Contrail widths are found to agree with observations. Measurements of contrail ice water content lie within the range of simulated values. Measurements may hint at larger mean ice water contents than our simulations but they may also be biased toward high values due to detection problems.

[52] We demonstrate the performance of the parameterization in an idealized experiment. Contrails are initiated, persist and spread in strongly supersaturated areas, get advected, increase their ice water content and disappear in less favorable atmospheric conditions. Contrail cirrus coverage is dominated by a few major events, contrail outbreaks, which have also been observed in nature. Contrail cirrus coverage therefore does not scale with contrail formation frequency but rather with ice supersaturation. These processes could not be studied using diagnostic contrail parameterizations. Even though in this experiment the lifetime of many contrail cirrus is short, contrail cirrus coverage is found to peak as late as $9 \mathrm{~h}$ after shutdown of air traffic. The average lifetime of contrail cirrus is therefore no indication for the time lag between contrail formation and maximum contrail coverage.

[53] Coverage due to young visible contrails is largest over the main traffic areas of Europe and North America. Owing to the prognostic treatment of contrail cirrus which allows the simulation of contrail advection those maxima are not as pronounced as in former GCM studies and contrail coverage is nonzero in areas free of air traffic. Our young contrail coverage is larger in the tropics and smaller in the extratropics than line shaped contrail coverage as estimated in the former studies. This is partly due to the use of a new potential contrail coverage parameterization that is consistent with the model's cloud scheme.

[54] Global coverage due to young visible contrails is $0.05 \%$ with an uncertainty due to changes in the spreading constant, age threshold and optical depth threshold of $0.02 \%, 0.01 \%$ and $0.03 \%$, respectively. The interannual variability of contrail cirrus coverage is large. The spread between different realizations within a month can be as large as the average value. This indicates that observations of line shaped contrail coverage over only a few months do not supply a good basis for model validation.

[55] The skill of the model simulating young contrail coverage was evaluated by comparing coverage due to young contrails with estimates of regional line shaped contrail coverage inferred from satellite images. The sensitivity of the simulated coverage to reasonable variations in two intrinsic parameters of the parameterization (spreading constant and initial contrail width), and to parameters governing the comparison with observational data (optical depth and contrail age threshold), is studied. Simulated young contrail coverage agrees very well with observations of line shaped contrail coverage over Europe and over the U.S.A. considering the interannual variability of contrail coverage and its sensitivity to the above parameters. Over the U.S.A. the seasonal cycle is reproduced as well. Over Japan in autumn and especially over the eastern North Pacific simulated young contrail coverage is much smaller than observed line shaped contrail coverage, whereas over Thailand mean values are well reproduced but the seasonal cycle is not well captured. One reason for the disagreement may be the fact that only over Europe, the North Atlantic and North America the flight inventory is reasonably reliable. Over the rest of the world the quality of the flight movement data set is lower. Over both eastern North Pacific and Japan, moisture fields and available water vapor do not restrict young contrail coverage and in fact support contrail cirrus (of any age) coverage that exceeds considerably the observed line shaped contrail coverage. An underestimation of the spreading of contrails and of the age threshold used to distinguish 'young', probably line shaped, contrails from others may contribute to the discrepancy, as well as uncertainties in the correction of observational line shaped contrail coverage. A more conclusive validation of simulated young contrail coverage would be possible if the errors connected with satellite derived estimates of line shaped contrail coverage were better known and different observational data sets were intercomparable. Furthermore, improved air traffic data sets would benefit the model simulations.

[56] This study was motivated by the need for independent and more physically based estimates of line shaped contrail coverage and the associated ice water content as well as their validation. Our parameterization allows the simulation of the contrail cirrus life cycle. In subsequent work we will study contrail cirrus of any age, their interaction with natural cirrus and the connected increase in high cloud coverage. The performance of the model to calculate contrail cirrus ice water content and optical depth will be further assessed as more data sets of global relevance become available.

[57] Acknowledgments. This work was performed within the DLR project "Climate-compatible air transport system" (CATS). We would like to thank Robert Sausen for motivating this study, Volker Grewe for help with the AERO2k data set and Michael Ponater, Klaus Gottschaldt and two anonymous reviewers for helpful comments on the manuscript.

\section{References}

Bakan, S., M. Betancor, V. Gayler, and H. Grassl (1994), Contrail frequency over Europe from NOAA satellite images, Ann. Geophys., 12, 962-968

Betancor-Gothe, M., and H. Grassl (1993), Satellite remote sensing of the optical depth and mean size of thin cirrus and contrails, Theor. Appl. Clim., 48, 101-113.

Boucher, O. (1999), Air traffic may increase cirrus cloudiness, Nature, 397, $30-31$.

Burkhardt, U., B. Kärcher, M. Ponater, K. Gierens, and A. Gettelman (2008), Contrail cirrus supporting areas in model and observations, Geophys. Res. Lett., 35, L16808, doi:10.1029/2008GL034056.

Carleton, A. M., D. J. Travis, K. Master, and S. Vezhapparambu (2008), Composite atmospheric environments of jet contrail outbreaks for the United States, J. Appl. Meteorol. Climatol., 47, 641-667.

Detwiler, A., and R. Pratt (1984), Clear-air seeding: Opportunities and strategies, J. Weather Mod., 16, 46-60.

Duda, D. P., P. Minnis, L. Nguyen, and R. Palikonda (2004), A case study of the development of contrail clusters over the Great Lakes, J. Atmos Sci., 61, 1132-1146. 
Duda, D. P., P. Minnis, and R. Palikonda (2005), Estimated contrail frequency and coverage over the contiguous United States from numerical weather prediction analyses and flight track data, Meteorol. Z., 14 , $537-548$

Dürbeck, T., and T. Gerz (1996), Dispersion of aircraft exhausts in the free atmosphere, J. Geophys. Res., 101, 26,007-26,015.

Eleftheratos, K., C. S. Zerefos, P. Zanis, D. S. Balis, G. Tselioudis, K. Gierens, and R. Sausen (2007), A study on natural and manmade global interannual fluctuations of cirrus cloud cover for the period 1984-2004, Atmos. Chem. Phys., 7, 2631-2642.

Eyers, C. J., P. Norman, J. Middel, M. Plohr, S. Michot, K. Atkinson, and R. A. Christou (2004), AERO2k global aviation emissions inventories for 2002 and 2025, Tech. Rep. QINETIC/04/01113, QinetiQ Ltd., Farnborough, U.K.

Febvre, G., et al. (2009), On optical and microphysical characteristics of contrails and cirrus, J. Geophys. Res., 114, D02204, doi:10.1029/ 2008JD010184

Forster, P., et al. (2007), Changes in atmospheric constituents and in radiative forcing, in Climate Change 2007: The Physical Science Basis. Contribution of WG I to the 4th Assessment Report of the IPCC, edited by S. Solomon et al., Cambridge Univ. Press, New York.

Freudenthaler, V., F. Homburg, and H. Jäger (1995), Contrail observations by ground-based scanning Lidar: Cross-sectional growth, Geophys. Res. Lett., 22, 3501-3504.

Gayet, J.-F., J. Ovarlez, V. Shcherbakov, J. Ström, U. Schumann, A. Minikin, F. Auriol, A. Petzold, and M. Monier (2004), Cirrus cloud microphysical and optical properties at southern and northern midlatitudes during INCA, J. Geophys. Res., 109, D20206, doi:10.1029/ 2004JD004803.

Gettelman, A., E. J. Fetzer, A. Eldering, and F. W. Irion (2006), The global distribution of supersaturation in the upper troposphere from the Atmospheric Infrared Sounder, J. Clim., 19, 6089-6103.

Gierens, K., R. Sausen, and U. Schumann (1999a), A diagnostic study of the global distribution of contrails. Part II: Future air traffic scenarios, Theor. Appl. Climatol., 63, 1-9.

Gierens, K., U. Schumann, M. Helten, H. G. J. Smit, and A. Marenco (1999b), A distribution law for relative humidity in the upper troposphere and lower stratosphere derived from three years of MOZAIC measurements, Ann. Geophys., 17, 1218-1226.

Heymsfield, A. J., R. P. Lawson, and G. W. Sachse (1998), Growth of ice crystals in a precipitating contrail, Geophys. Res. Lett., 25, 1335-1338.

Jensen, E. J., A. S. Ackerman, D. E. Stevens, O. B. Toon, and P. Minnis (1998), Spreading and growth of contrails in a sheared environment J. Geophys. Res., 103, 13,557-13,567.

Kärcher, B., R. Busen, A. Petzold, F. P. Schröder, U. Schumann, and E. J. Jensen (1998), Physicochemistry of aircraft-generated liquid aerosols, soot and ice particles: 2. Comparison with observations and sensitivity studies, J. Geophys. Res., 103, 17,129-17,148.

Kästner, M., R. Meyer, and P. Wendling (1999), Influence of weather conditions on the distribution of persistent contrails, Meteorol. Appl., 6, $261-271$.

Land, C., M. Ponater, R. Sausen, and E. Roeckner (1999), The ECHAM4.L39 (DLR) atmosphere GCM-Technical description and model climatology, DLR-FB 1999-31, 45 pp., Deutsches Zentrum für Luft- und Raumfahrt, Cologne, Germany.

Lewellen, D. C., and W. S. Lewellen (2001), The effects of aircraft wake dynamics on contrail development, J. Atmos. Sci., 58, 390-406.

Lohmann, U., P. Stier, C. Hoose, S. Ferrachat, S. Kloster, E. Roeckner, and J. Zhang (2007), Cloud microphysics and aerosol indirect effects in the global climate model ECHAM5-HAM, Atmos. Chem. Phys., 7, 3425-3446.

Mannstein, H., R. Meyer, and P. Wendling (1999), Operational detection of contrails from NOAA AVHRR data, Int. J. Remote Sens., 20, $1641-1660$.

Marquart, S. (2003), Klimawirkung von Kondensstreifen: Untersuchungen mit einem globalen atmosphärischen Zirkulationsmodell, doctoral thesis (in German), Deutsches Zentrum für Luft- und Raumfahrt, $161 \mathrm{pp}$ Cologne, Germany.

Marquart, S., M. Ponater, F. Mager, and R. Sausen (2003), Future development of contrail cover, optical depth, and radiative forcing: Impacts of increasing air traffic and climate change, J. Clim., 16, 2890-2904.

Meyer, R., H. Mannstein, R. Meerkötter, U. Schumann, and P. Wendling (2002), Regional radiative forcing by line-shaped contrails derived from satellite data, J. Geophys. Res., 107(D10), 4104, doi:10.1029/ 2001JD000426

Meyer, R., R. Buell, C. Leiter, H. Mannstein, S. Pechtl, T. Oki, and P. Wendling (2007), Contrail observations over Southern and Eastern Asia in NOAA/AVHRR data and comparisons to contrail simulations in a GCM, Int. J. Remote Sens., 28, 2049-2069.

Minnis, P., D. F. Young, D. P. Garber, L. Nguyen, W. L. Smith Jr., and R. Palikonda (1998), Transformation of contrails into cirrus during SUCCESS, Geophys. Res. Lett., 25, 1157-1160.

Minnis, P., R. Palikonda, B. J. Walter, J. K. Ayers, and H. Mannstein (2005), Contrail properties over the eastern North Pacific from AVHRR data, Meteorol. Z., 14, 515-523.

Myhre, G., and F. Stordal (2001), On the tradeoff of the thermal and solar radiative impact of contrails, Geophys. Res. Lett., 28, 3119-3122.

Palikonda, R., P. Minnis, D. P. Duda, and H. Mannstein (2005), Contrail coverage derived from AVHRR data over the continental United States of America and surrounding areas, Meteorol. Z., 14, 525-536.

Ponater, M., S. Marquart, and R. Sausen (2002), Contrails in a comprehensive global climate model: Parameterization and radiative forcing results, J. Geophys. Res., 107(D13), 4164, doi:10.1029/2001JD000429.

Rädel, G., and K. Shine (2007), Evaluation of the use of radiosonde humidity data to predict the occurrence of persistent contrails, $Q$. J.R. Meteorol. Soc., 133, 1413-1424.

Rädel, G., and K. Shine (2008), Radiative forcing by persistent contrails and its dependence on cruise altitudes, J. Geophys. Res., 113, D07105, doi:10.1029/2007JD009117.

Roeckner, E., K. Arpe, L. Bengtsson, M. Christoph, M. Claussen, L. Dümenil, M. Esch, M. Giorgetta, U. Schlese, and U. Schulzweida (1996), The atmosphere general circulation model ECHAM-4: Model description and simulation of present-day climate, Max-Planck-Inst. Meteorol. Rep. 218, 90 pp., Hamburg, Germany.

Sassen, K. (1997), Contrail-cirrus and their potential for regional climate change, Bull. Am. Meteorol. Soc., 78, 1885-1903.

Sassen, K., and B. S. Cho (1992), Subvisual thin cirrus lidar data set for satellite verification and climatological research, J. Appl. Meteorol., 31, $1275-1285$

Sausen, R., K. Gierens, M. Ponater, and U. Schumann (1998), A diagnostic study of the global distribution of contrails, Part I: Present day climate, Theor. Appl. Climatol., 61, 127-141.

Sausen, R., et al. (2005), Aviation radiative forcing in 2000: An update on IPCC (1999), Meteorol. Z., 14, 555-561.

Schiller, C., M. Krämer, A. Afchine, N. Spelten, and N. Sitnikov (2008), Ice water content of Arctic, midlatitude and tropical cirrus, J. Geophys. Res., 113, D24208, doi:10.1029/2008JD010342.

Schröder, F., B. Kärcher, C. Duroure, J. Ström, A. Petzold, J.-F. Gayet, B. Strauss, P. Wendling, and S. Borrmann (2000), On the transition of contrails into cirrus clouds, J. Atmos. Sci., 57, 464-480.

Schumann, U. (1996), On conditions for contrail formation from aircraft exhausts, Meteorol. Z., 5, 4-23.

Schumann, U. (2000), Influence of propulsion efficiency on contrail formation, Aerosp. Sci. Technol., 4, 391-401.

Schumann, U. (2005), Formation, properties and climate effect of contrails, C. R. Phys., 6, 549-565.

Schumann, U., J. Ström, R. Busen, R. Baumann, K. Gierens, M. Krautstrunk, F. P. Schröder, and J. Stingl (1996), In situ observations of particles in jet aircraft exhausts and contrails for different sulfur containing fuels, J. Geophys. Res., 101, 6853-6869.

Spichtinger, P., K. Gierens, U. Leiterer, and H. Dier (2003), Ice supersaturation in the tropopause region over Lindenberg, Germany, Meteorol. Z., $12,143-156$.

Spinhirne, J. D., W. Hart, and D. P. Duda (1998), Evolution of the morphology and microphysics of contrail cirrus from airborne remote sensing, Geophys. Res. Lett., 25, 1153-1156.

Stubenrauch, C. J., and U. Schumann (2005), Impact of air traffic on cirrus coverage, Geophys. Res. Lett., 32, L14813, doi:10.1029/2005GL022707.

Stuber, N., and P. Forster (2007), The impact of diurnal variations of air traffic on contrail radiative forcing, Atmos. Chem. Phys., 7, 3153-3162. Sundqvist, H. (1978), A parameterization scheme for non-convective condensation including prediction of cloud water content, $Q . J$. R. Meteorol. Soc. $104,677-690$.

Sussmann, R., and K. Gierens (2001), Differences in early contrail evolution of two-engine versus four-engine aircraft: Lidar measurements and numerical simulations, J. Geophys. Res., 106, 4899-4911.

Unterstrasser, S. (2008), Numerische Simulationen von Kondensstreifen und deren Übergang in Zirren, doctoral thesis (in German), Ludwig Maximilians Univ. München, München, Germany.

U. Burkhardt and B. Kärcher, Institut für Physik der Atmosphäre, Deutsches Zentrum für Luft- und Raumfahrt, Oberpfaffenhofen, D-82234 Wessling, Germany. (ulrike.burkhardt@dlr.de) 